Supporting information

\title{
Quantitative LC-MS/MS Glycomic Analysis of Biological Samples Using AminoxyTMT ${ }^{\mathrm{TM}}$
}

Shiyue Zhou ${ }^{1}$, Yunli Hu ${ }^{1}$, Lucas Veillon ${ }^{1}$, Sergei I. Snovida ${ }^{2}$, John C. Rogers ${ }^{2}$, Julian Saba $^{3}$ and Yehia Mechref ${ }^{*}$

1. Department of Chemistry and Biochemistry, Texas Tech University, Lubbock, TX, 79415

2. Thermo Fisher Scientific, Rockford, IL, 61102

3. Thermo Fisher Scientific, San Jose, CA, 95134

*Corresponding author

Department of Chemistry and Biochemistry

Texas Tech University

Lubbock, TX 79409-1061

Email: yehia.mechref@ttu.edu

Tel: 806-742-3059

Fax: 806-742-1289 
Figure and table legend

Table S1. The structures of glycans derived from pooled human blood serum, with MS2 spectrum and calculated variation. Symbols: $\square$, N-acetylglucosamine (GlcNAc); $\bigcirc$, Galactose (Gal); $\nabla$, Fucose (Fuc); ○, Mannose (Man); ○, Glucose (Glc); $\diamond, \mathrm{N}$ acetylneuraminic acid (NeuAc/Sialic Acid); $\diamond, N$-glycolylneuraminic acid (NeuGc).

Table S2. Quantitative changes in the abundance of glycans derived from the blood serum of esophagus patients $v s$. sex- and age-matched blood serum of disease free subjects. EAC. Esophageal Adenocarcinoma Patients; BE, Barrett's Esophagus Patients; HGD, High-Grade Dysplasia Patients

Table S3. Information of 6 cell lines used in quantitative analysis.

Table S4. Quantitative changes in the abundance of glycans derived from 6 different cell lines.

Figure S1. Collision energy test for HCD; different type of labeled glycans were fragmented at different collision energy values. Symbols: as in Table S1.

Figure S2. . Extracted ion chromatograms of aminoxyTMT ${ }^{\mathrm{TM}}$ labeled N-glycans derived from fetuin and tandem MS spectrum for triantennary tri-sialylated glycan. Symbols: as in Table S1.

Figure S3. Extracted ion chromatograms of aminoxyTMT ${ }^{\mathrm{TM}}$ labeled N-glycans derived from RNase B and tandem MS spectra of $\mathrm{Man}_{5}$ GlcNAc $_{2}$ and Man GlcNAc $_{2}$. Symbols: as in Table S1.

Figure S4. Tandem MS spectra of sodiated N-glycans derived from RNase B. Symbols: as in Table S1. 
Table S1

\begin{tabular}{|c|c|c|}
\hline \multicolumn{3}{|c|}{ High mannose type } \\
\hline $\begin{array}{c}\text { N-glycan } \\
\text { Structure }\end{array}$ & $\begin{array}{c}\text { Reporter ion } \\
\text { Spectrum }\end{array}$ & $\begin{array}{c}\text { Variation } \\
\% \text { error }\end{array}$ \\
\hline & $8 \%$ \\
\hline & & \\
\hline & & \\
\hline & \\
\hline
\end{tabular}




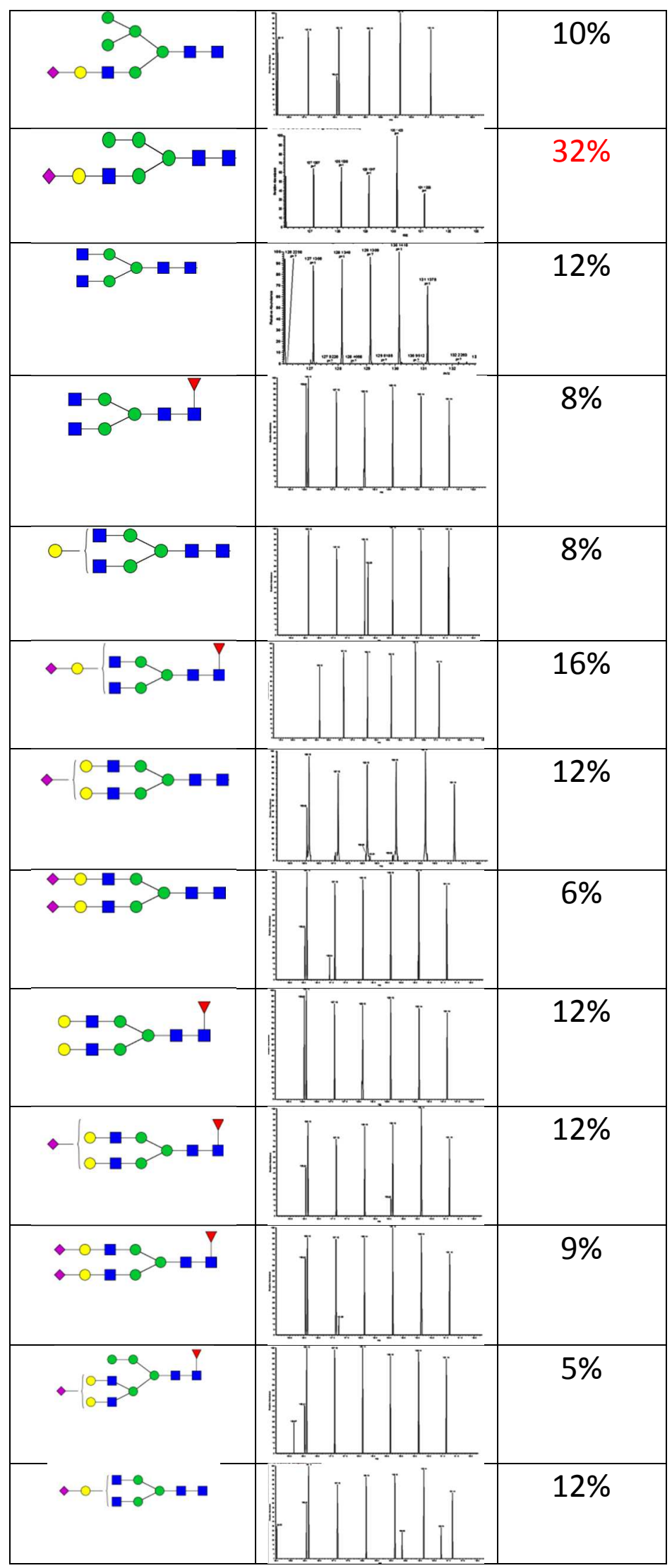




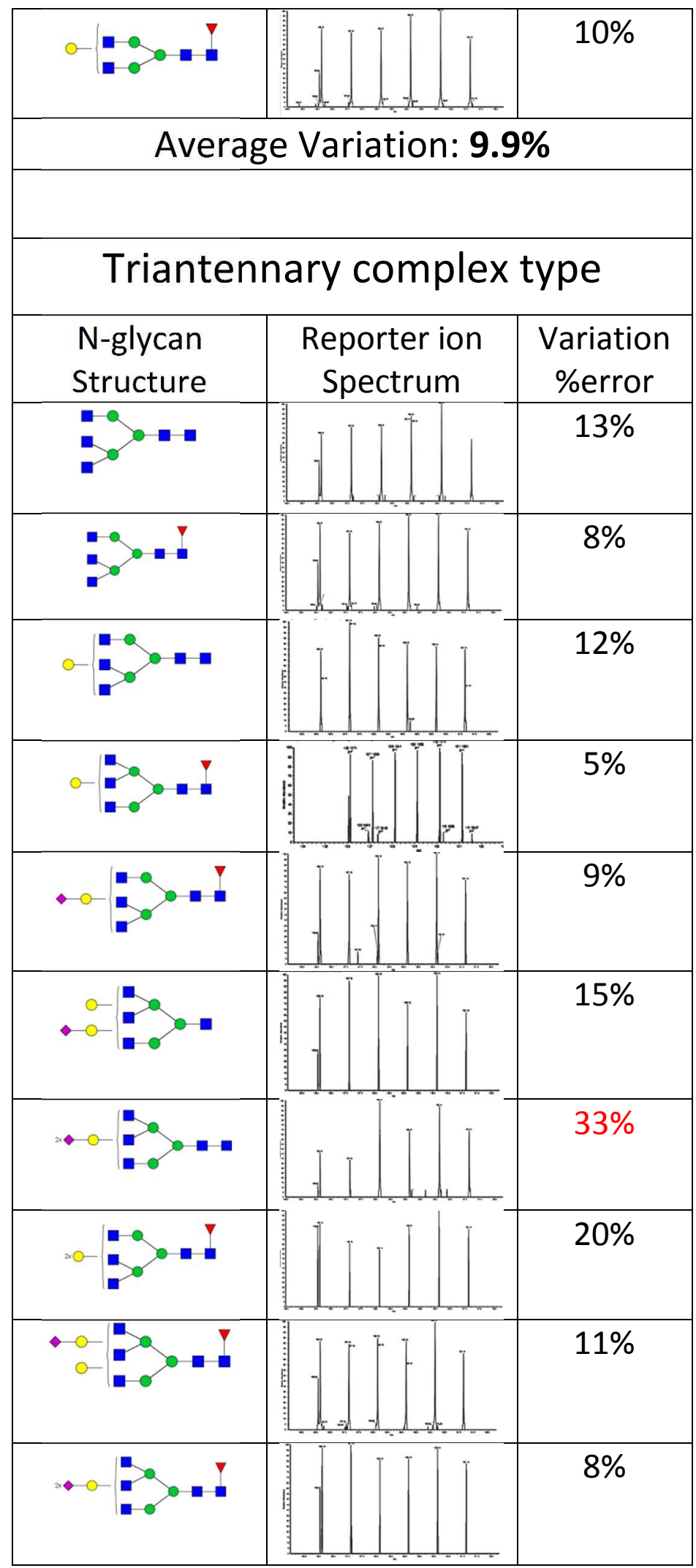




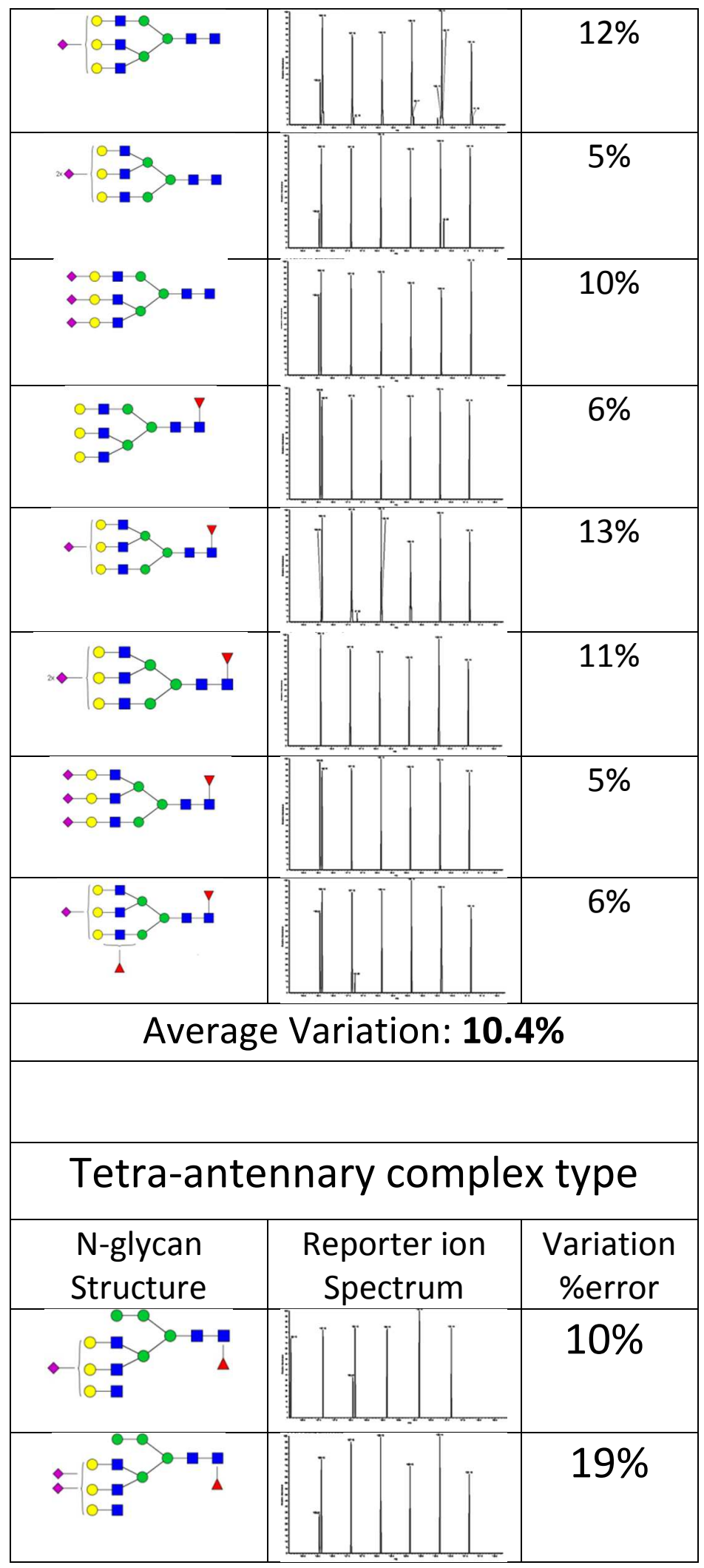




\begin{tabular}{|c|c|c|}
\hline & \multicolumn{1}{|c|}{$7 \%$} \\
\hline & Average Variation: $\mathbf{1 2 \%}$ \\
\hline
\end{tabular}


Table S2.

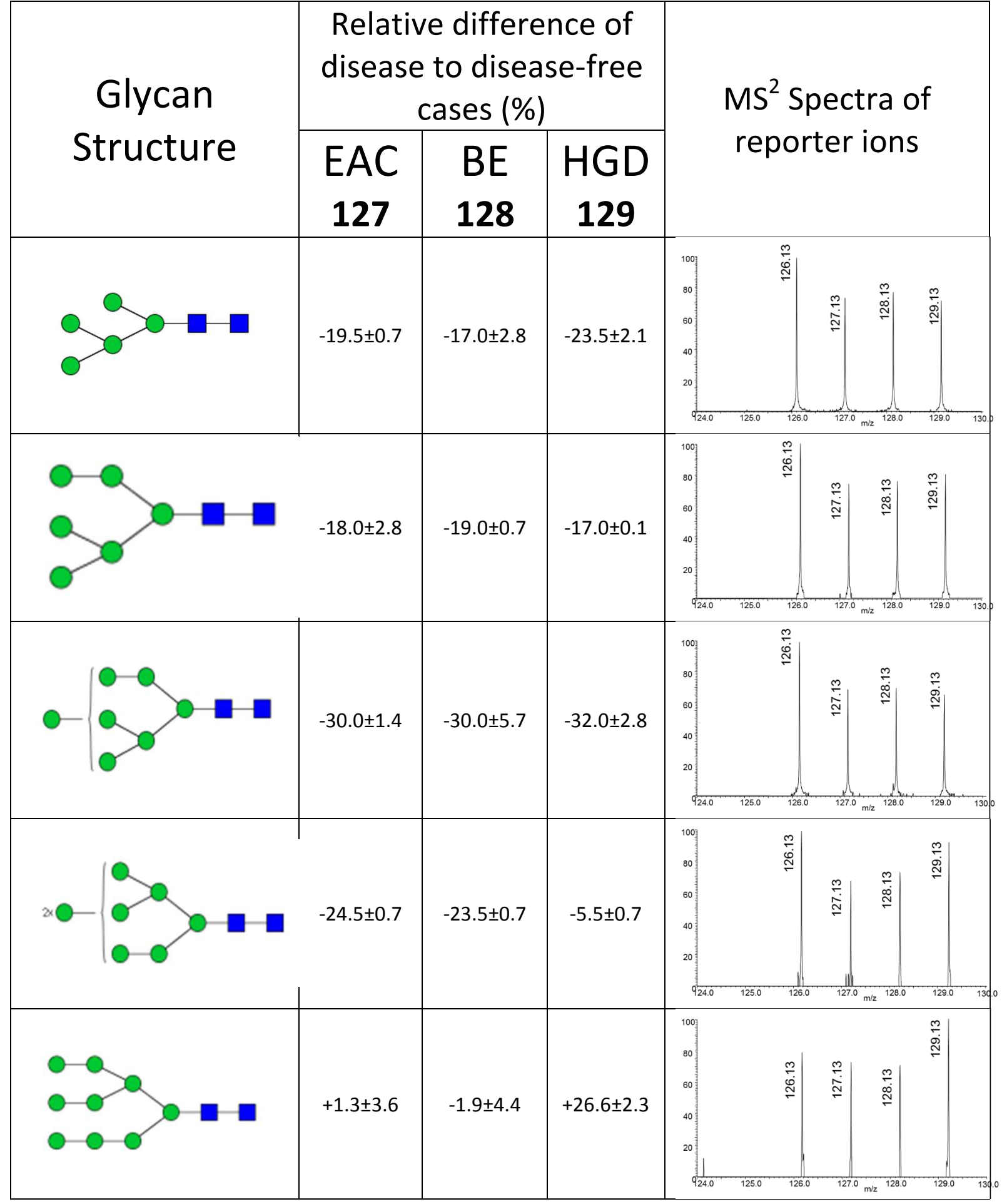




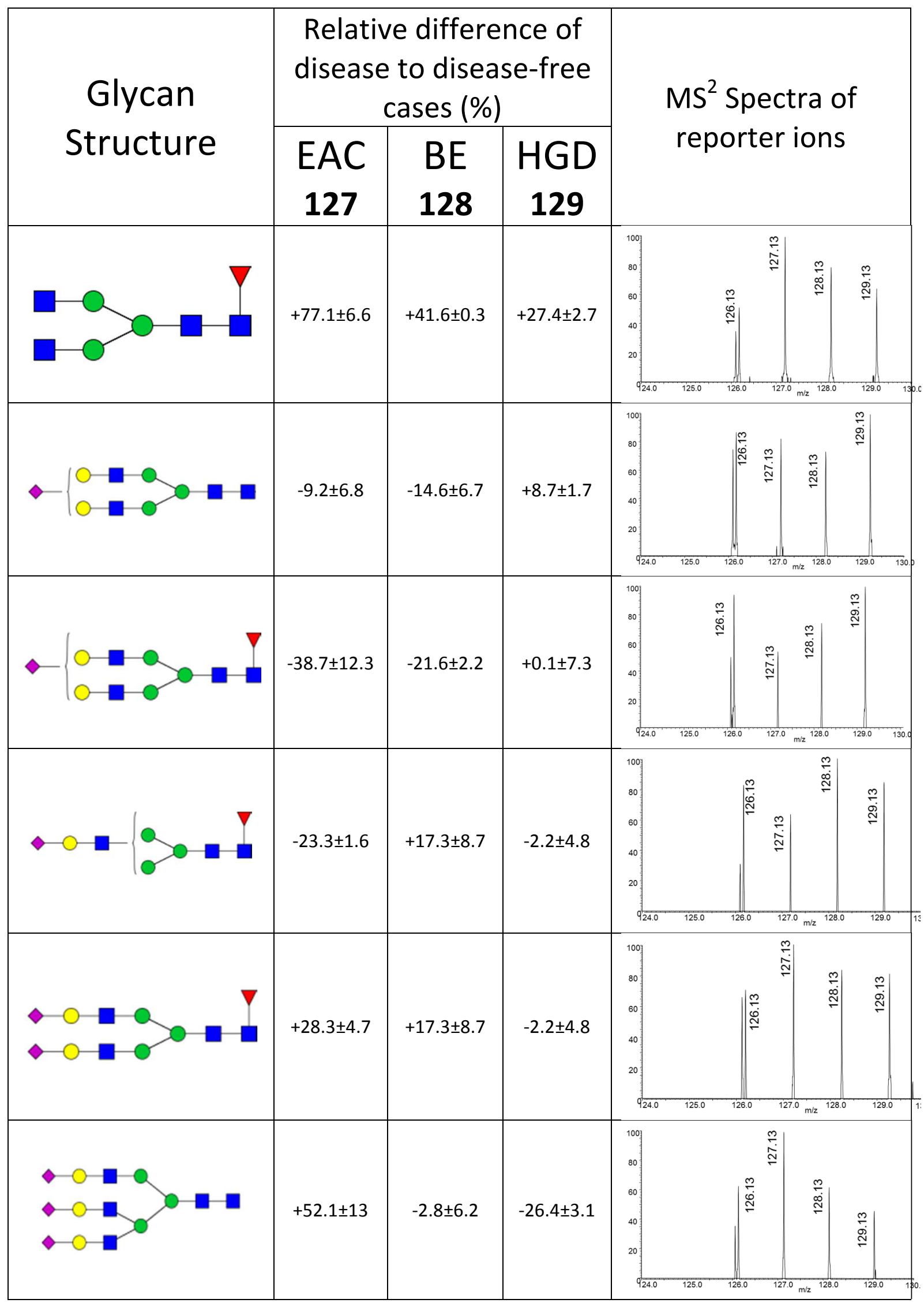




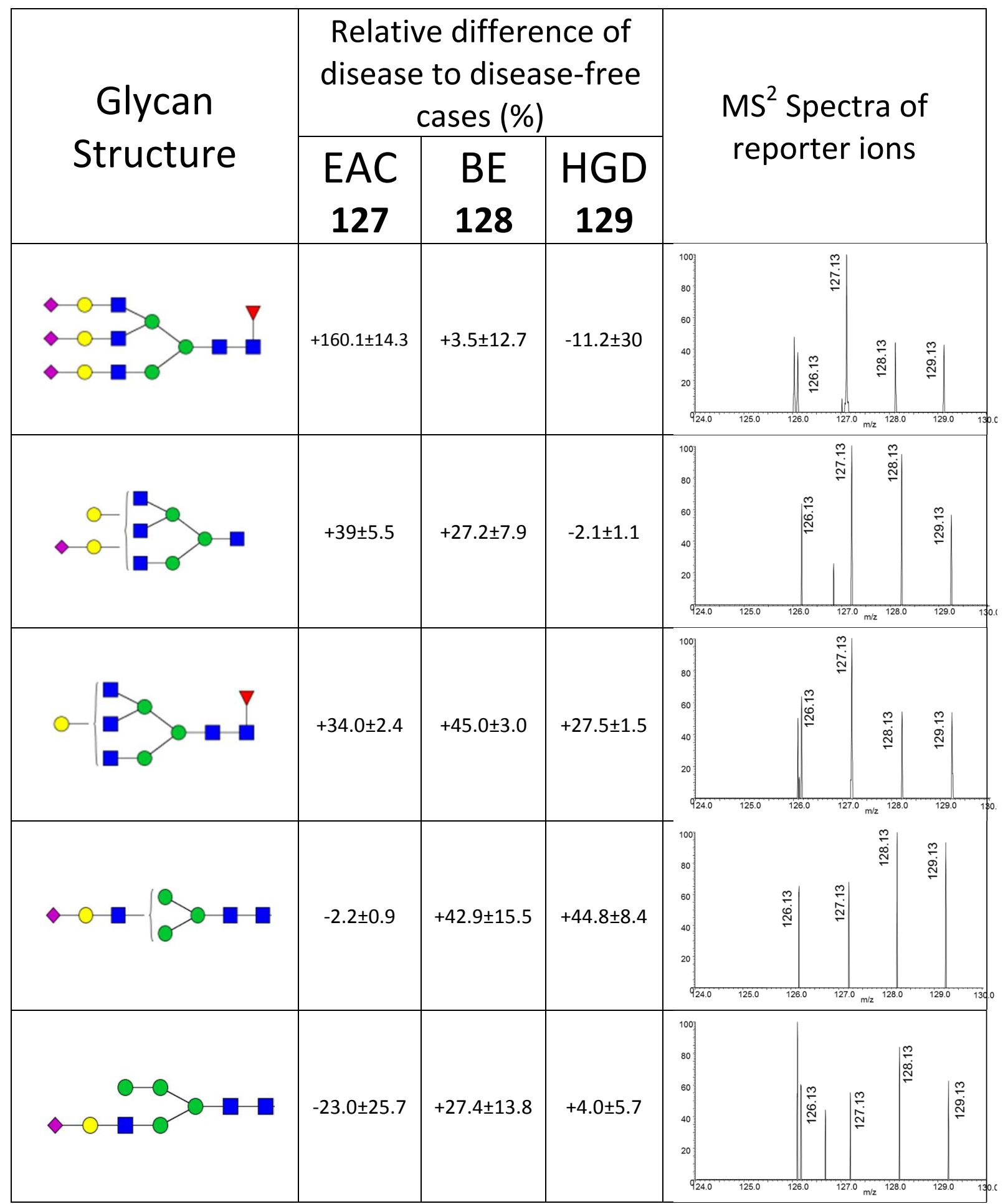




\begin{tabular}{|c|c|c|c|c|}
\hline Cell Line & ER & PR & HER2 & Description \\
\hline MDA-MB-231BR & - & - & - & Subline of 231 , brain targeting metastatic \\
\hline MDA-MB-231 & - & - & - & $\begin{array}{c}\text { Breast cancer cell line, } \\
\text { non-specific metastatic derived from } \\
\text { metastatic site: pleural effusion }\end{array}$ \\
\hline MDA-MB-361 & + & + & + & $\begin{array}{l}\text { Breast cancer cell line, } \\
\text { derived from metastatic site: brain }\end{array}$ \\
\hline CRL-1620 & $\mathrm{N} / \mathrm{A}$ & N/A & $\mathrm{N} / \mathrm{A}$ & Brain cancer cell line \\
\hline HTB-131 & - & - & - & $\begin{array}{c}\text { Breast cancer cell line, } \\
\text { derived from metastatic site: pericardial } \\
\text { effusion }\end{array}$ \\
\hline HTB-22 & - & - & - & $\begin{array}{l}\text { Breast cancer cell line, } \\
\text { derived from a carcinoma of the breast }\end{array}$ \\
\hline
\end{tabular}


Table S4

\begin{tabular}{|c|c|c|c|c|c|c|}
\hline $\begin{array}{c}\text { HexNAc-Hex- } \\
\text { DeHex-Neu5Ac }\end{array}$ & $\begin{array}{c}\text { MDA-MB- } \\
231 \mathrm{BR}\end{array}$ & $\begin{array}{c}\text { MDA- } \\
\text { MB-231 }\end{array}$ & $\begin{array}{c}\text { MDA- } \\
\text { MB-361 }\end{array}$ & $\begin{array}{c}\text { CRL- } \\
1620\end{array}$ & HTB-131 & HTB-126 \\
\hline $2-5-0-0$ & $100 \%$ & $66 \%$ & $78 \%$ & $47 \%$ & $68 \%$ & $56 \%$ \\
\hline $2-6-0-0$ & $100 \%$ & $97 \%$ & $68 \%$ & $41 \%$ & $114 \%$ & $109 \%$ \\
\hline $2-7-0-0$ & $100 \%$ & $100 \%$ & $44 \%$ & $65 \%$ & $81 \%$ & $85 \%$ \\
\hline $2-8-0-0$ & $100 \%$ & $107 \%$ & $50 \%$ & $68 \%$ & $109 \%$ & $107 \%$ \\
\hline $2-9-0-0$ & $100 \%$ & $135 \%$ & $78 \%$ & $77 \%$ & $89 \%$ & $92 \%$ \\
\hline $3-3-1-0$ & $100 \%$ & $65 \%$ & $10 \%$ & $70 \%$ & $10 \%$ & $19 \%$ \\
\hline $4-3-1-0$ & $100 \%$ & $47 \%$ & $6 \%$ & $35 \%$ & $15 \%$ & $32 \%$ \\
\hline $4-4-0-0$ & $100 \%$ & $82 \%$ & $18 \%$ & $15 \%$ & $41 \%$ & $24 \%$ \\
\hline $4-5-0-1$ & $100 \%$ & $106 \%$ & $30 \%$ & $36 \%$ & $100 \%$ & $18 \%$ \\
\hline $4-5-1-1$ & $100 \%$ & $151 \%$ & $124 \%$ & $49 \%$ & $162 \%$ & $65 \%$ \\
\hline $4-5-0-2$ & $100 \%$ & $30 \%$ & $29 \%$ & $8 \%$ & $18 \%$ & $18 \%$ \\
\hline $5-5-0-1$ & $100 \%$ & $19 \%$ & $156 \%$ & $8 \%$ & $11 \%$ & $6 \%$ \\
\hline $4-5-1-2$ & $100 \%$ & $53 \%$ & $18 \%$ & $15 \%$ & $41 \%$ & $12 \%$ \\
\hline $5-6-0-3$ & $100 \%$ & $68 \%$ & $32 \%$ & $38 \%$ & $157 \%$ & $0 \%$ \\
\hline $5-6-1-3$ & $100 \%$ & $60 \%$ & $10 \%$ & $15 \%$ & $35 \%$ & $25 \%$ \\
\hline $5-6-0-4$ & $100 \%$ & $146 \%$ & $92 \%$ & $42 \%$ & $83 \%$ & $75 \%$ \\
\hline $5-6-1-2$ & $100 \%$ & $57 \%$ & $14 \%$ & $29 \%$ & $50 \%$ & $11 \%$ \\
\hline
\end{tabular}


Figure S1
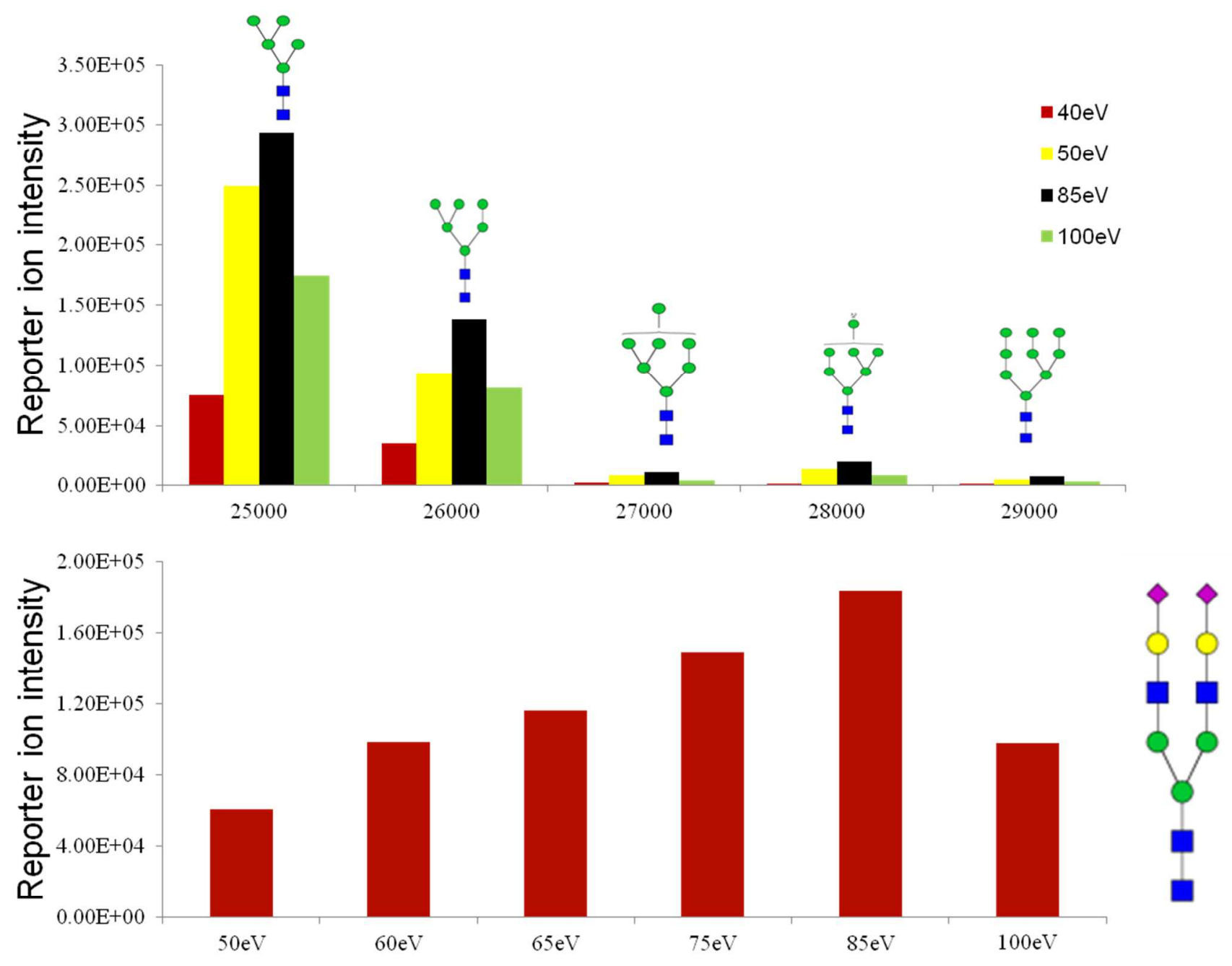
Figure S2
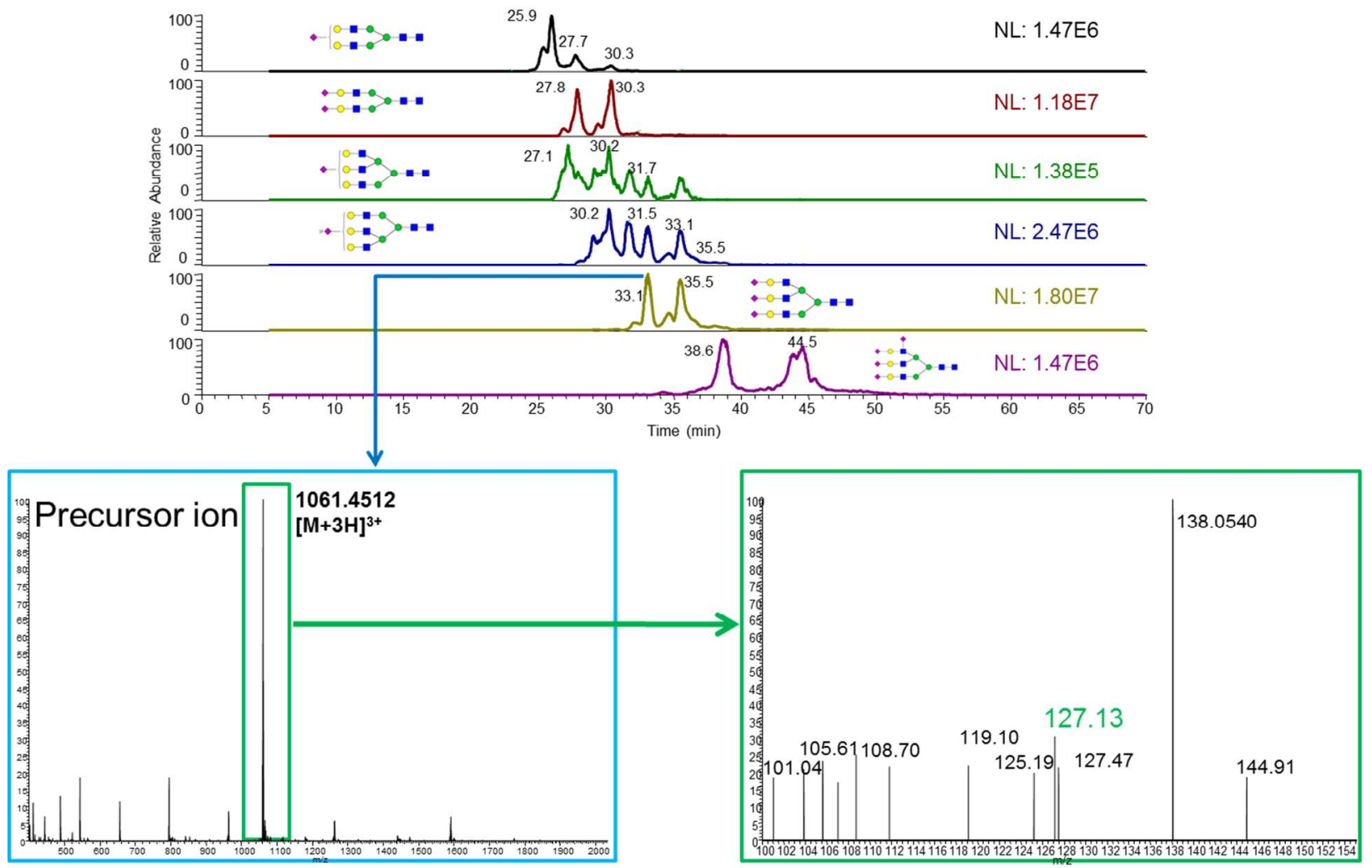
Figure S3

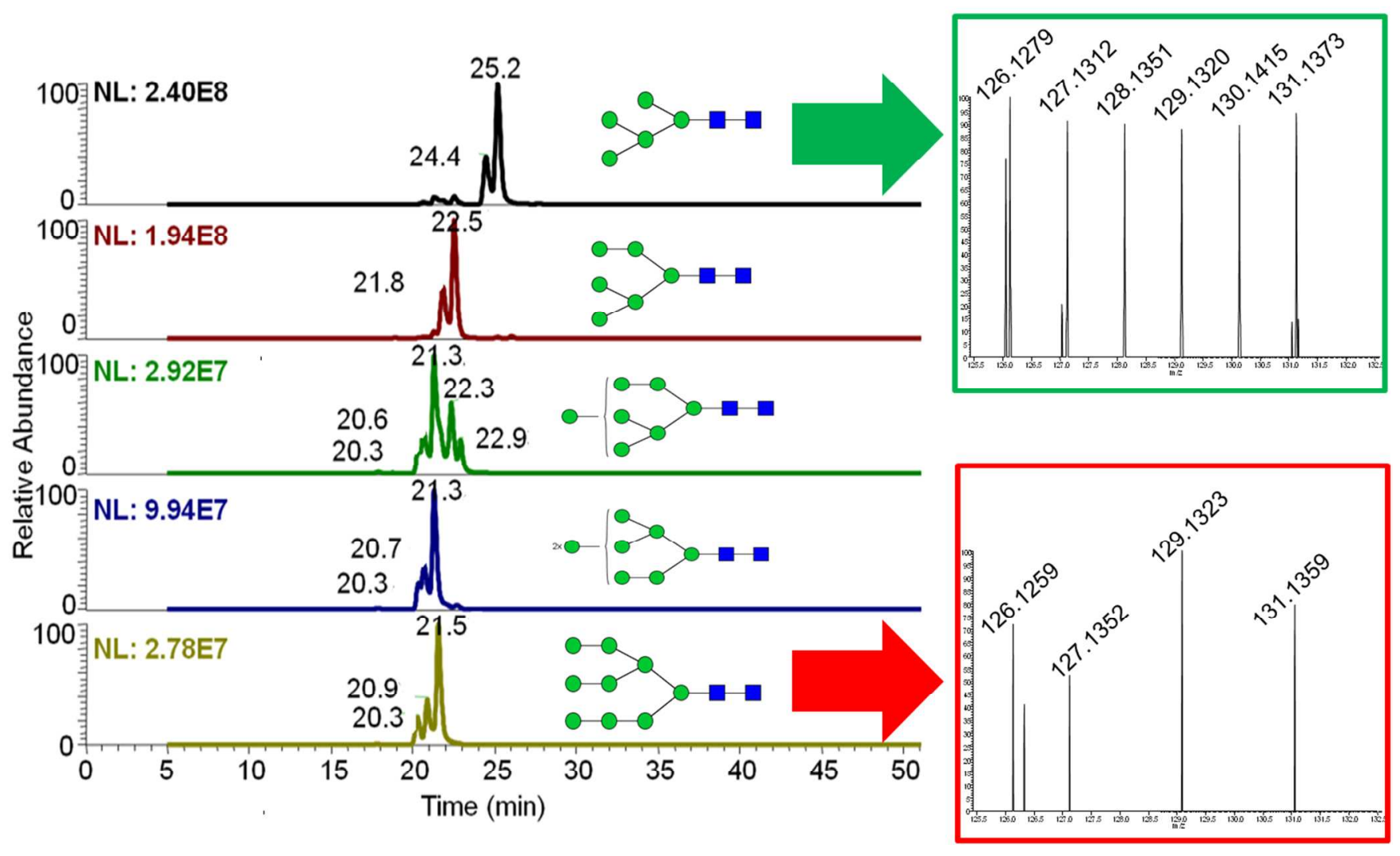


Figure S4
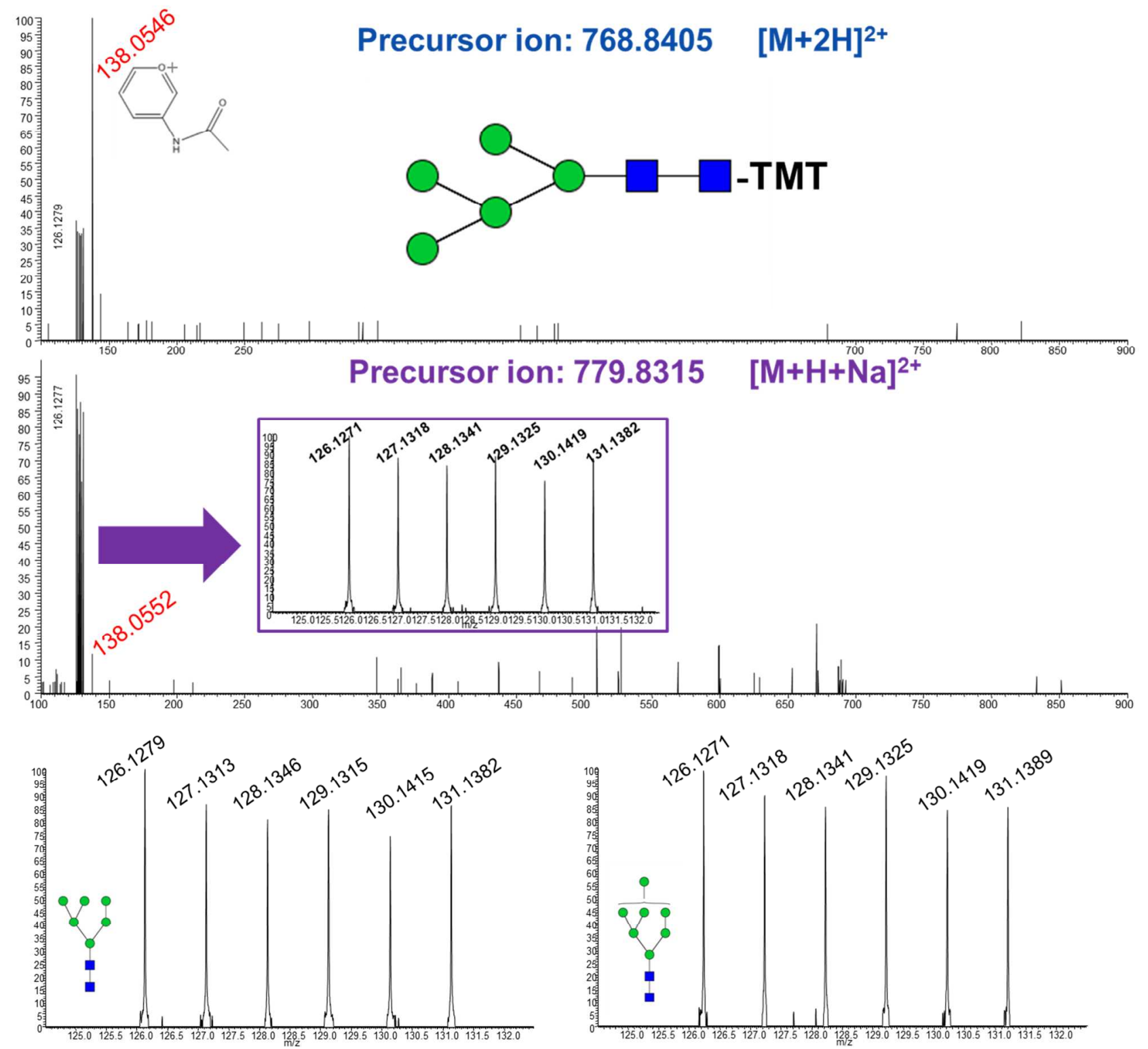

\section{$[\mathrm{M}+\mathrm{H}+\mathrm{Na}]^{2+}$}
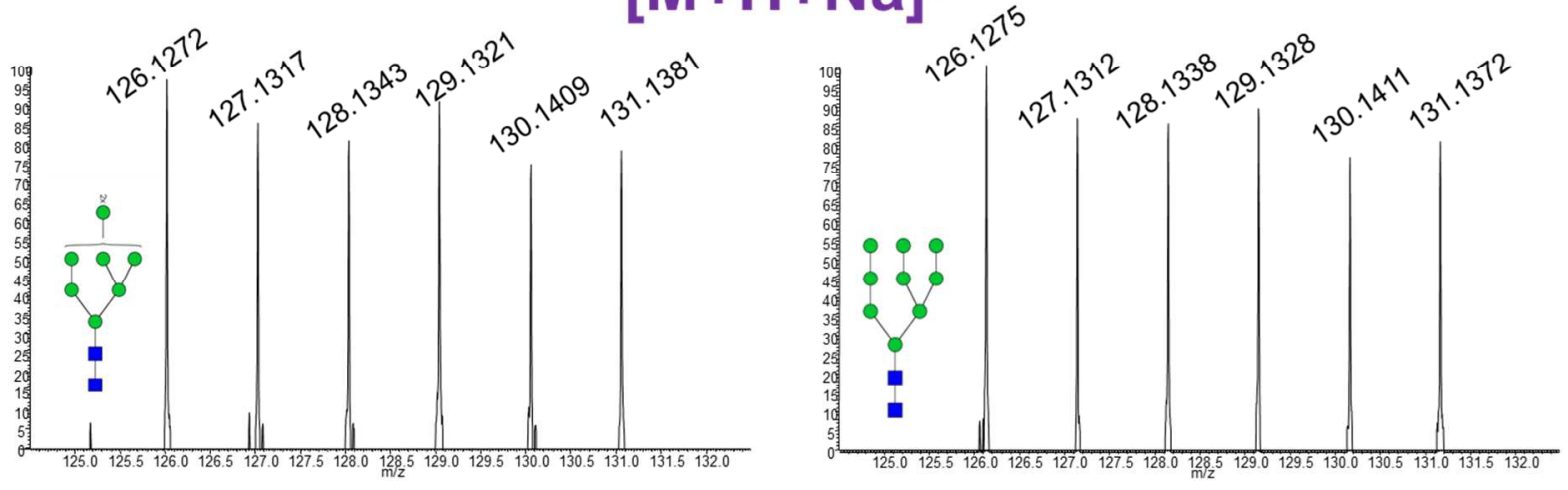